\title{
LA POESÍA VIAJA A AMÉRICA: LA “ALOCUCIÓN” LÍRICA DE ANDRÉS BELLO
}

\author{
Vicente Cervera Salinas \\ Universidad de Murcia
}

\begin{abstract}
Resumen: Una visión completa del fenómeno histórico de la Independencia de los países americanos no puede desatender el universo poético. El gran polígrafo y humanista venezolano Andrés Bello publicó la "silva" "Alocución a la poesía” en la revista que él mismo fundó durante su larga estancia londinense de diecinueve años, la mítica Biblioteca Americana en su primer número de 1823. Este artículo recupera aquella publicación y analiza sus elementos compositivos, formales e históricos. En ella, Bello reclama el viaje del género lírico a la prometedora tierra de América, donde renovará sus energías, ya marchitas en el Viejo Mundo, y contribuirá a robustecer la "autonomía cultural”, compañera y guía de la "autonomía política" de "Nuestra América".
\end{abstract}

Palabras clave: Andrés Bello, poesía, revistas americanas, autonomía cultural, Filosofía de la Historia.

Abstract: A complete overview of the historical phenomenon of the Independence of Latin American countries cannot disregard the poetic universe. The great Venezuelan humanist and polygraph Andrés Bello published the "silva" "Alocución a la Poesía" in the magazine he founded during his nineteen-year stay in London, the legendary Biblioteca Americana, in its first issue in 1823. This article recovers that publication and analyzes its compositional, formal and historic elements. In it, Bello claims the journey of poetry to the promised land of America, where it will renew its energies, withered in the Old World, and contribute to strengthen the "cultural autonomy", companion and guide of the "political autonomy" of "Nuestra América".

Keywords: Andrés Bello, poetry, American magazines, cultural autonomy, Philosophy of History.

Que la poesía sea un arma cargada de futuro es declaración de principios por todos conocida y por algunos aceptada. Que el sentido de dicho verso tenga un valor plurivalente puede ser, empero, motivo de reflexión. Un futuro que no se asocie unívocamente al territorio de lo fáctico o de las realidades empíricas podría involucrar acepciones múltiples a la orientación de ese futuro que la poesía como cuerpo verbal encarna. Arma de conocimiento filosófico y aun científico 
fue la poesía para los pensadores griegos de la era presocrática, cuando el vate ritmaba en pies métricos y ráfagas de inspiración su concepción sobre la naturaleza y sus elementos generadores, determinando con autores como Parménides de Elea las categorías de la verdad y la apariencia. Para el pueblo latino la poesía fue un arma repleta de documentación histórica (Tito Livio), de ficción política (Virgilio) y de lucubración materialista (Lucrecio) y en la literatura medieval activó todos los resortes de la teología, con el Alighieri a la cabeza, para desembocar en instrumento de construcción del ser cortesano en su versión caballeresca profana o mística a partir del Renacimiento. Bien mirado, hasta el siglo XIX, con el despertar romántico, siempre fue la poesía estandarte del futuro y vehículo para la acción. A partir de la poética de Hegel y de la identificación entre poesía lírica y sujeto e interioridad, pareció relegarse su ámbito al recreo intimista de las emociones, evocaciones y sentimientos del ser que conjuraba con la palabra musical las experiencias y los sueños, aunque también es notaria la afición romántica al discurso de estirpe idealista y de entonación universal.

No es de extrañar, por tanto, que también en la lírica hispanoamericana pueda asociarse la propensión armada del género poético con el pensamiento henchido de fuerza en pos de un ideal de alcance histórico, político y continental, como sucede en el repertorio poético de Andrés Bello y, más concretamente, en su "Alocución a la poesía", donde, de modo diáfano y vehemente, fluye el verso hacia un futuro que él mismo activa en aventura visionaria y, a la vez, de fuerte calado intelectual. Firmemente convencido de que el discurso estrófico propende a emancipar la realidad, crea el ínclito humanista americano una extraordinaria "silva" donde la convicción de su pensamiento dispara municiones y saetas que materializan un porvenir inspiradamente vislumbrado por las almas libertarias que diseñaron la historia de la independencia americana. La "Alocución a la poesía" despliega en sí misma un manifiesto, reviste la naturaleza de un ensayo transubstanciado en expresión poética y funda semántica y culturalmente un concepto axial en la historia hispanoamericana: el concepto de "epifanía interna". Con él quiero aludir al proceso de auto-conocimiento o auto-gnosis que experimentaron las naciones y pueblos de América en la voluntad de manifestarse ante sí mismas, aspirando a reconocerse y descubrir quiénes y cómo eran sin necesidad de recurrir a modelos foráneos o a dependencias ajenas. Este proceso es paralelo históricamente, pero inverso en su orientación, al que se produjo en el momento de la colonización, durante los primeros siglos de la conquista; es decir, la simétrica y opuesta "epifanía externa", mediante la cual América se dio a conocer "urbi et orbi" al Viejo Mundo, a través de las noticias que llegaban de los conquistadores y, sobre todo, gracias a la inmensa labor de los Cronistas de Indias. La "epifanía interna”, por el contrario, incoa un sentido nítido de independencia, de autonomía, no sólo política, sino también cultural. Este hecho, remarcado en los estudios sobre Bello, fue especialmente distinguido por Pedro Henríquez Ureña que plasmó las concomitancias entre la "Alocución" de Bello 
y el famoso discurso "The American Scholar" de Ralph Waldo Emerson, como ensayos seminales en el ámbito de las dos Américas, pletóricos de vigor en la salutación optimista a un despertar, a un alba, a un inicio esperanzado para las naciones que entraban en su mayoría de edad ${ }^{1}$.

De hecho, en las páginas de crítica literaria que conforman el corpus teórico del erudito venezolano es frecuente hallar referencias al fenómeno de la escritura en verso como preámbulo de una arqueología del saber donde la poesía fungía de transmisión de la historia con sus sucesivos mecanismos de transformación del mundo, procedimiento que él aplicará en esta silva. Dice al respecto Bello en su fino análisis de la obra épica de Alonso de Ercilla: "Los rapsodos griegos, los escaldos germánicos, los bardos bretones, los troveres franceses, y los antiguos romanceros castellanos, pertenecieron desde luego a la clase de poetas historiadores, que al principio se propusieron simplemente versificar la historia: que la llenaron de cuentos maravillosos y de tradiciones populares, adoptados sin examen y generalmente creídos; y que después, engalanándola con sus propias invenciones, crearon poco a poco y sin designio un nuevo género, el de la historia ficticia"2.

A un tercer subgénero de la poesía de raigambre épica correspondería la silva "Alocución a la poesía", que el polígrafo publicara en la revista que él mismo fundó durante su larga estancia londinense de diecinueve años, la mítica $B i$ blioteca Americana, junto al colombiano Juan García del Río, en su primer número de $1823^{3}$. Me refiero a la poesía histórico-visionaria, forjada como arma cargada de porvenir inminente, ya que su construcción verbal sostiene el anda-

1 "Como Emerson en su conferencia sobre The American Scholar (1837), piensa (Bello) que "hemos prestado demasiada atención a las cortesanas musas de Europa". Procede a describir la riqueza natural del Nuevo Mundo y la proeza de los libertadores, que estaban librando aún su última campaña. Eran éstos nuevos temas de poesía. Las pacíficas sombras imperiales de Virgilio y Horacio son sus guías en este intento revolucionario, juntamente con los escritores dieciochescos que hacen literatura de los temas científicos". P. Henríquez Ureña, Historia cultural y literaria de la América Hispánica, edición de V. Cervera Salinas, Madrid, Verbum, 2007,121-122.

2 A. Bello, Antología, edición, introducción y notas de G. Bellini, Madrid, Castalia, 2009, 152.

3 Como precisamente documenta Pedro Henríquez Ureña en Las corrientes literarias de la América Hispánica. "muchos años después, el argentino Juan María Gutiérrez, crítico e historiador de la cultura, reprodujo el poema como introducción declaratoria en nuestra primera gran antología, la América poética (Valparaíso, 1846)" (Op. cit., 122). Por su parte, Antonio Cussen relata así la aparición del poema: "El primer número de la Biblioteca Americana, publicada en julio de 1823, fue un lujoso volumen de 470 páginas con varias estampas a color de escenas del Nuevo Mundo. Frente a la primera página hay una litografía que muestra una mujer en atavío clásico que visita a una mujer indígena de pechos desnudos y plumas en la cabeza. (...) La primera pieza en el número inaugural de la Biblioteca es un poema de Bello: "Alocución a la Poesía”, en que se introducen las alabanzas de los pueblos americanas que más se han distinguido en la guerra de la independencia. (Fragmento de un poema inédito titulado "América"). En el primer volumen, Bello publicó los primeros 447 versos del poema. Los restantes 387 versos abrían el segundo volumen de la publicación. Los originales manuscritos de la "Alocución" revelan que Bello completó una porción grande del poema entre 1821 y 1823, es decir, durante los años cuando trabajó como asistente de Irisarri”. A. Cussen, Bello y Bolivar, México, FCE, 1998, 119-120. 
miaje de la independencia cultural americana, extensión necesaria de los hechos reales que pautaron la historia de la emancipación política, legislativa e institucional. La obra poética de Andrés Bello - encomiada por referentes en la crítica filológica del XIX, como Miguel Antonio Caro, que realizó un enjundioso prefacio a un volumen de su lírica publicado en Madrid en 1881, y Marcelino Menéndez Pelayo, en el primer volumen de su Historia de la poesía hispano-americana-, completará de este modo un proceso de insurgencia independentista, que la propia prosa ensayística del autor produjo como aporte indiscutible a su desarrollo ${ }^{4}$. Y al hablar de prosa cabría incluir en su repertorio no sólo los ensayos específicos, discursos y artículos de prensa, sino también su labor educativa, vital para el conocimiento genuino de nuestro autor, y la correlativa actividad intelectual como gramático de la lengua, como jurista y como filósofo, tareas todas ellas que tenían como centro neurálgico de esa esfera el sentimiento de lo propiamente americano y la búsqueda denodada de la "autonomía cultural" para el continente .

Y así, la lengua española — sistematizada en su Gramática — vertebraría la diversidad continental de los pueblos; las leyes determinarían el espíritu nacional, en la tradición de los filósofos de la Enciclopedia, y muy especialmente en Montesquieu, y el pensamiento racional tendería a intensificar el vuelo especulativo de ese espíritu a través de una muy aquilatada Filosofía del entendimiento, donde

${ }^{4}$ Dice el erudito cántabro: "El carácter de estas Silvas de Bello ha sido perfectamente definido por D. Miguel A. Caro, llamándolas poesía científica, no en el sentido de que den la enseñanza de ningún arte o ciencia, en cuyo caso serían muy científicas, pero no poesía; sino en el sentido de que dan bella y viva y concreta realización a ciertos conceptos sobre la naturaleza, la moral y la historia, y se engalana con hermosas descripciones de objetos naturales y de labores humanas, fielmente ajustadas a la precisión y al rigor del conocimiento científico, pero interpretado y transformado éste por el espíritu poético, que es una manera ideal y bella de concebir, sentir y expresar las cosas, cualesquiera que ella sean". Y más adelante, añade con sutileza sin prejuicios: "Tal linaje de poesía es ciertamente tan legítimo como cualquier otro, cuando el poeta sabe encontrarle; y no hay razón para restringir los dominios del poeta..." (Menéndez Pelayo, Historia de la poesía hispano-americana, Madrid-Santander, CSIC, 1948, 369-370). Cabría conjeturar hasta qué punto no existió una cierta identificación de naturalezas científico-literarias entre el americano y el santanderino por parte de este último, sobre todo atendiendo a la defensa que de Bello realiza contra el ataque de quienes le vituperaron su excesiva formación y cultura, ya que -según Menéndez Pelayo- "por haber representado en América un tipo más puro de la educación clásica, y la más alta magistratura en lo tocante a la lengua, fue aquel gran maestro blanco de las iras de todos los insurrectos literarios, de todos los niveladores democráticos, y hubo quien, como el famoso argentino Sarmiento, se atreviese a pedir en letras de molde su perpetuo ostracismo de América por el crimen capital e inexpiable de saber demasiado y de ser demasiado literato" (ibid., 357).

5 Interesante resulta la comparación que anota Fernando Murillo en su biografía del enciclopedista Bello, entre su caudaloso pensamiento y el río del país donde nació: "Había sido comparado al Orinoco, por el caudal poderoso de su mente, prodigado como las aguas del gran río en muchos afluentes. Unos siguieron su curso y regaron los terrenos en que debía surgir la gran transformación del país. Otros dieron vida en una acción que tomó muchos años a los frutos de su estudio, los que pueden llamarse sus obras mayores". F. Murillo, Andrés Bello, Madrid, Historia 16-Quorum, 1987, 87. 
hallamos — -según José Gaos- lo más granado del pensamiento reflexivo americano ${ }^{6}$, y que para Juan David García Bacca coronaría la voluntad de articular un sistema completo de conocimiento que "en vano había esperado hicieran otros en Francia, Inglaterra o España" 7 . Al respecto, resulta altamente ilustrativo el ensayo que publicó Bello en el diario chileno El Araucano, ya en 1848, cuando la definición de esa "autonomía cultural" era imperativo categórico de la realidad americana, y savia natural de su reconocimiento ante el mundo y, sobre todo, ante sí propia. Y así, casi medio siglo antes de que José Martí donase al mundo su emblemático ensayo Nuestra América, declaraba el venezolano: "Nuestra civilización será también juzgada por sus obras; y si se la ve copiar servilmente a la europea aun en lo que ésta no tiene de aplicable, ¿cuál será el juicio que formará de nosotros, un Michelet, un Guizot? Dirán: la América no ha sacudido aún sus cadenas; se arrastra sobre nuestras huellas con los ojos vendados; no respira en sus obras un pensamiento propio, nada original, nada característico; remeda las formas de nuestra filosofía, y no se apropia su espíritu. Su civilización es una planta exótica que o ha chupado todavía sus jugos a la tierra que la sostiene"8.

Esta hermosa declaración de principios, este ensayo fue originalmente publicado bajo el título de "Modo de escribir la historia". El tiempo, no obstante, ha ido modificándolo en su transmisión, legándose a las siguientes generaciones como "Autonomía cultural de América", término afianzado por Pedro Henríquez Ureña y sancionado por Leopoldo Zea en su antológica edición de las Fuentes de la cultura latinoamericana. Finísimo en su modo de perfilar el problema de la independencia cultural, Bello articula de modo implícito una sutil distinción que será desarrollada explícitamente por Germán Arciniegas, un siglo más tarde, en su monográfico ensayo El pensamiento vivo de Andrés Bello (1946), donde establece la necesidad de diferenciar las dos columnas del proceso emancipador, es decir, la específica de la acción bélica y la no siempre bien distinguida de la revolución mental y espiritual que, en suma, fue la que pudo propiciar la primera. Así lo expresa el colombiano:

6 "Porque en la historia del pensamiento en lengua española, la Filosofía del entendimiento representa la manifestación más importante de la filosofía hispanoamericana influida por la europea anterior al idealismo alemán y contemporáneo de ésta hasta la positivista”. Gaos en A. Bello, Filosofía del entendimiento, introducción de J. Gaos, México, FCE, 2006, 10.

7 "Filosofía comprendía, pues, según Bello, dos partes: 1) Filosofía del entendimiento, integrada por Psicología Mental y Lógica; y 2) Filosofía moral, cuyas partes tenían que ser Psicología moral y Ética.

No emprende, pues, Bello, la redacción ni de un Ensayo, ni de unos Elementos, o de un Tratado sobre los principios; sino una obra en grande y total: una Filosofía. (...) Desgraciadamente sólo pude terminar la primera parte de su plan”. García Bacca en A. Bello, Filosofía del entendimiento, en Obras Completas, vol. III, prólogo de J. D. García Bacca, Caracas, Ministerios de Educación, 1951, xxxii.

8 A. Bello, "Las repúblicas hispanoamericanas"y "Autonomía cultural de América”, en L. Zea, comp., Fuentes de la cultura latinoamericana, vol. I, México, FCE, 1995, 194. 
En la historia de América hay dos hechos de orden muy diferente: el uno es la Revolución de Independencia y el otro es la Guerra de Independencia. En los libros, estos dos hechos suelen confundirse por falta de un criterio científico que venga a disociar términos que, algunas veces, llegan a ser contradictorios. La revolución no se reduce a provocar el desprendimiento político de España. Quiere reaccionar contra un sistema de filosofía que considera caduco, abomina de una escolástica que juzga insuficiente, tiene la ambición de precipitar a las nuevas generaciones de América en la corriente vertiginosa de las ciencias contemporáneas, se enamora de las matemáticas, de las ciencias naturales, opone el contrato social de Rousseau al derecho divino de los reyes, implica una revisión de todos los conceptos tradicionales9.

Se trata, pues, de derogar la simplicidad a la hora de abordar el fenómeno independentista hispanoamericano, en favor de una mirada lúcida que constate la trascendencia que tuvo lo que, en términos de Arciniegas, fuera la "emancipación espiritual". Recordemos que Bello está produciendo lo más granado de su obra, atendiendo a esta dirección concreta que aquí propongo, en la década de los años treinta y cuarenta del XIX, figurando, por tanto, como un pionero en la función seminal que tendrá la literatura y el ensayismo en todo el frente histórico de la separación política ${ }^{10}$. Y, en este contexto, es necesario insistir en la capital firmeza que para tal empresa cabe atribuir a su obra poética y, más concretamente, a su "Alocución a la poesía", que será, de todas las suyas, la silva donde el pensamiento se imbrica de modo más cabal y sólido con la novedad del impulso lírico y, a su vez, donde dicha motivación involucra fuerzas generatrices que conformarán la realidad futura. La poesía, en este caso, por lo tanto, no sólo abarca la dimensión expresiva en su versión más elevada y áurea, sino que activa resortes mágicos para transformar el "dictum" lírico en formas vivas de la realidad (no desacertaba Arciniegas al concebir genéricamente su obra como el "pensamiento vivo" de Andrés Bello). Poesía, al fin, como epos histórico-visionario, según la definición anterior, o - si lo preferimos-, poesía como arma colmada de futuro. Y ello se evidencia en las primeras estrofas de la "Alocución", aquellas que entonan apóstrofes a la "divina poesía" para que renuncie a su morada europea y viaje, transoceánica, hasta los parajes del feraz y aun enigmático

9 G. Arciniegas, El pensamiento vivo de Andrés Bello, Buenos Aires, Losada, 1958, 9.

10 En 1829 embarcó con su familia desde Londres hasta Valparaíso. En Chile residiría hasta su muerte, acaecida el 15 de octubre de 1865. Estos años publica, entre otras muchas, sus Principios de derecho de gentes (1832), Principios de ortologia y métrica de la lengua castellana (1835), Gramática castellana destinada al uso de los americanos (1847), además de sus numerosísimos ensayos y su participación en el diario chileno El Araucano, del que sería nombrado director en 1850. Además, en 1842 dictaría su curso de filosofía, que sería el germen de su magna obra Filosofía del entendimiento, publicada póstuma e íntegramente en 1881. Mas, como dice Fernando Murillo, "todo lo dicho sobre cuanto ocupó sus días en la última y más larga etapa de su vida no debe hacer olvidar que Bello fue un poeta, algo que no eclipsó su consagración a materias científicas ni su desvelo para ser útil en la transformación social". Así, "en Chile escribió mucha poesía o continuó versiones al castellano de obras de otros poetas que había comenzado antes” (Murillo, op. cit., 110-111). 
lar americano ${ }^{11}$. Habitadora, según Bello, de "la soledad", término embriagado de resonancias gongorinas, es invocada la Poesía, de raíz siempre sobrehumana, a desdeñar "la culta Europa, / que tu nativa rustiquez desama", dirigiendo el vuelo propicio "adonde te abre/ el mundo de Colón su grande escena". La inocente Natura, que activa el paradigma del imaginario americano en el poema, se opone a la "región de luz y miseria", en la que establece Bello el paradigma opuesto, es decir, el europeo, en esa curiosa asociación de complementos, "luz" y "miseria", donde cabe reconocer las grandeza del pensamiento liberal, masónico y enciclopédico que dictó el "siglo de las luces" y de las revoluciones, al mismo lado de a la "miseria" de un modelo de pensamiento ajeno al ámbito de lo natural. En tal modelo ya periclitado para la existencia poética se enseñorea, en cambio, su más cara rival, la Filosofía, que en la silva se presenta como una sui generis "reina de la noche" que somete "la virtud a cálculo" y cuyo imperio es dominado por los atributos de la inversión de los valores estrictamente puros y naturales. Es decir, la filosofía como dueña y señora del orbe europeo propicia el reino del cambio y la dislocación del pensamiento recto y la justa actuación en las naciones, por lo que los principios se mudan y trastruecan en un delirio propio de los infamantes sueños quevedescos: "donde la libertad vano delirio, / fe, la servilidad, grandeza el fasto, / la corrupción cultura se apellida"12. Léase, el dominio de los intereses creados, el teatro de las maravillas que ensalza la impostura coronándola en la cátedra de una verdad falsaria y fementida. El paradigma inverso sería, siguiendo el argumento, el ámbito preclaro en que la libertad, la fe, la grandeza y la cultura son originarias, no han sido aún mancilladas por el peso de los contratos sociales y brillan en su prístino y nativo fulgor. Es decir, el lugar — todavía "con límites" - que faculta el resurgimiento de una nueva edad para la poesía y aun para la vida, espacio utópico, pero al mismo tiempo real, en que los frutos naturales y la inocencia de la Natura rimen y ritmen con los dones ya granados de la evolución espiritual de la sociedad: la "mens sana" de la poesía, liberada del lastre de una filosofía utilitarista y pragmática, en el "corpore sano" de un territorio, de un continente puro y virginal. Es decir, América. No olvidemos que el poema fue escrito entre lúgubres paredes londinenses, en la época

11 Cuando se habla de poesía europea, cabría subrayar la manifiesta aversión de nuestro poeta hacia la afectación y el manierismo retórico de la poesía española y, por ende, de la americana que proseguía su modelo. La nueva expresión que invoca Bello en relación a la poesía en lengua española promovería -según Fernando Paz Castillo, en su edición del primer volumen de las Obras Completas del venezolano, editadas en Caracas en los años cincuenta del siglo xx- la reacción ante la mimesis de "formalismos retóricos, aprendidos de segunda mano en imitadores de Góngora, sin que esto expresara nobleza alguna de dicción, ni penetrase en la inmensidad de la naturaleza del Nuevo Mundo, llena de majestad imponente e inesperada mansedumbre. Para Bello tales afectaciones venían de la decadente poesía española. De allí que dijera en su célebre Alocución que era llegado el tiempo para que las Musas dejaran la culta Europa y se volvieran al mundo de Colón”. Paz Castillo en Bello, Poesías, en Obras Completas, vol. I., prólogo de F. Paz Castillo, Caracas, Ministerio de Educación, 1952, 1xii-lviii.

12 Bello, 2009, op. cit., 74-75. 
tan certeramente recreada por Arturo Uslar Pietri en su ensayo biográfico, “Andrés Bello, el desterrado"13.

Nuestro humanista insta y aun exige a la poesía iniciar ese recorrido geográfico pero, sobre todo, histórico y revolucionario, para reconocer con él el triunfo real de una emancipación en la dimensión del pensamiento y para levantar, en suma, el edificio de la ya mentada "autonomía cultural". "Y sobre el vasto Atlántico tendiendo/ las vagarosas alas, a otro cielo, / a otro mundo, a otras gente te encamina, / do viste aún su primitivo traje/ la tierra, al hombre sometida apenas" (vv. 53-67) ${ }^{14}$. Una libertad, en este caso la de la tierra, que se ensalza para agradar al propio itinerario de la poesía, que habrá de reconocer en esta gran finca del porvenir, tal como concibe el humanista a América, su lugar atávico de origen, pudiendo al cabo radicar, liberándose de las hojas muertas pero también de las raíces podridas, que le impedían seguir creciendo en Europa y, aún es más, que la desposeían de su riqueza, desalmándola en su esencia. El modelo que preside el imaginario lírico del poeta supone, empero, un regreso a la fuente prístina del canto lírico, ya que el lugar nativo de las "rustiqueces" poéticas quedará asimilado en el poema al que decretaran los líricos latinos, y en especial Horacio y, sobre todo, Virgilio, cuyas obras fueran admiradas y traducidas por Bello ${ }^{15}$. La exaltación virgiliana del paisaje rural halla cobijo en la imaginación del poeta americano como el "locus amoenus" ideal al que regresar en este viaje de ida y vuelta de la poesía que en su "alocución" nos propone. Una "ida", un viaje hacia América que plantea real y efectivo: un viaje que, en verdad, será extraordinariamente reconocido por la gran obra poética hispanoamericana de finales del XIX

13 "Aquel hombre hermoso, robusto y tranquilo que llega a Londres en el umbral de la treintena, acaba de abandonar su paisaje, su familia, sus costumbres, su lengua. Ya no va por las calles soleadas y coloridas de la Caracas de su adolescencia, sino por las húmedas y neblinosas avenidas donde a la media tarde flotan los faroles como coágulos de luz amortecida. (...) En lugar de los bosques del Catuche y de Chacao, de los rojos bucares, de los inmensos cedros, de las mecidas palmeras, las fantasmales arboledas esfumadas en niebla y agua de Hyde Park; y en vez del materno castellano criollo con sus claras sílabas abiertas, lo rodeaba el ahogado rumor de aquella lengua gutural y apelmazada.

Aquella nueva etapa de su vida, que llegó a ser larga de diecinueve años, fue la de la pobreza, el abandono y la soledad. Después de unos breves meses esplendorosos en los que Bolívar derrochaba el dinero en los que se reunían con las con las más célebres personalidades en la casa de Miranda en Grafton Square (...) vinieron los largos años de pobreza y de estudio, de mucha niebla, muchos libros y pan escaso, en que el hombre de traje raído se refugiaba en su mesa del British Museum...”. A. Uslar Pietri, "Andrés Bello el desterrado", en L. Zea, comp., Fuentes de la cultura latinoamericana, vol. II, México, FCE, 1995, 461.

14 Bello, 2009, op. cit., 75.

15 Sobre la inmensa obra traductora de Andrés Bello, es interesante rescatar unas iluminadoras páginas de la introducción de Pedro Grases a la edición de su Obra literaria en Ayacucho (P. Grases en Bello, 1985, xxxviii-xxxix), donde no sólo encomia la traducción propiamente dicha, sino también los juiciosos apuntes sobre el arte de traducir, partiendo de las versiones que realizara de los poetas clásicos latinos y griegos. Según Grases, tal vez el más notable logro del polígrafo en esta disciplina humanística lo hallaríamos en su versión del poema La oración de Todos, de su admirado Víctor Hugo. 
y, muy en especial, durante el siglo XX. A esta luz, la "Alocución" se anticiparía en su figuración épico-visionaria a la aparición de poetas que, de modo genuino y borgesiano, pueden hoy en día releerse a la luz del texto de Bello, como es el caso de Pablo Neruda y en concreto, de su Canto General. Estrechando un lazo invisible entre la geórgica virgiliana, la égloga de Garcilaso y el cántico a la historia general americana de Neruda, pronostica el erudito el devenir de la poesía en América, y fantasea con la deseada llegada de "algún Marón americano" que sea el amanuense del estro poético en el continente emancipado y, en cuya lira, "también las mieses, los rebaños cante,/ el rico suelo al hombre avasallado,/ y las dádivas mil con que la zona/ de Febo amada al labrador corona"16.

Según la lectura de Antonio Cussen, en su iluminador volumen Bello y Bolivar, no cabría duda acerca de la identificación de dicha referencia virgiliana con el mismo autor del texto, siendo así los versos geórgicos y épicos de la "Alocución" un anuncio de su siguiente poema, que le convertiría en autor central en la lírica hispanoamericana del XIX, la silva "Agricultura en la zona tórrida", texto que también abriría las páginas de otra revista por él fundada, en este caso El Repertorio americano, en octubre de 1826 . No se trataría, a mi entender, de ofuscar la claridad meridana en dicha ecuación, pero sí cabría matizar, desde el punto de vista que propongo en este trabajo, el sentido de los versos de Bello en una clave de porvenir que trascendería al autor histórico y que vendría a plantear el destino lírico del género en un continente que incorporará la creación poética de un modo ya definitivo y autóctono, respondiendo así al verdadero sentido de la "alocución", que no es sino la llamada a la mudanza geográfica y, por ende, cultural de la poesía. De este modo, el Virgilio Marón de América no debería ser circunscrito al autor del poema, sino que proyectaría visionariamente nombres que serían convocados en sus estrofas y que, con el tiempo, responderían a su llamado: pensemos en Rubén Darío, en Alfonso Reyes o en el ya aludido Pablo Neruda, por citar tan sólo figuras insignes y egregias de la "expresión americana”, en el sentido más netamente lezamiano del término. Referencias que, a su vez, comportarían de modo extremo la acepción más lata del término "héroe", corroborando así el soplo épico que domina la segunda parte del poema, y sin olvidar la correlación que estableciera Thomas Carlyle al conjugar la acción heroica en términos literarios y humanísticos.

No en vano, críticos y editores actuales de la obra de Bello, como lo es Giuseppe Bellini en la edición antológica de 2009, insisten en el estudio de la recepción de la obra del venezolano en este escenario del cumplimiento de su presagio que estamparían grandes autores del siglo XX a partir de nociones incoadas por Bello en su "Alocución", algunas de las cuales remiten a un concepto sensorial y anticipador de la literatura exuberante de la siguiente centuria: "Artista extraordinario, en este breve cuadro Bello" - dice Bellini refiriéndose a una descripción de productos agrícolas en el seno de su "Alocución"— solicita en el

16 Bello, 2009, op. cit., 80. 
lector varios sentidos: vista, olfato, oído, debido a la armonía del verso. Un bodegón extraordinario, posible fuente de inspiración, en el siglo XX, para Alejo Carpentier en su novela El recurso del método (...). Y eso sin descartar - añade Bellini- la posible influencia, como punto de arranque, sobre Neruda, para su grandiosa celebración de América"17. Al fin y al cabo, cabría deducir, Andrés Bello faculta en su "Alocución" un puente poético para la gesta literaria; saluda - como los poetas que en limbo dantesco vieron reaparecer a Virgilio ante ellos ${ }^{18}$ - al "altissimo poeta" que vendrá, dignificando la esencia renovada y la mudanza geográfica de la Poesía. Pero en ese puente está él mismo cantando las glorias y hazañas de la independencia; pero en ese puente está inseminando las voces que después de él habrán de completar el acto mágico-visionario del viaje, del traslado de la Divina Poesía hasta América. En el pretil del mismo hallamos el arte poética del propio Bello, que, a su vez, viaja a la semilla latina y funda el género poético de la emancipación americana. Está él, en efecto, pero acompañado por las sombras de Horacio y Virgilio, como también lo estuviera el Dante, y por las voces de los poetas que él convocó aunque no pudiera ver. Nosotros sî podemos. La visión completa de este puente de palabras nos lo permite el devenir del tiempo. Los últimos versos de su vasta silva reflejan este aspecto de poeta-hacedor de realidades presentes y futuras, que abre en su poema una brecha que él mismo estima fecunda en la acción y prolongada en el tiempo: "Así el que osare con tan rico asunto/ medir las fuerzas, dudaré qué nombre/ cante primero, qué virtud, qué hazaña; / y a quien la lira en él y la voz pruebe, / sólo dado será dejar vencida/ de tanto empeño alguna parte breve" (vv. 793-798). No olvidemos la circunstancia de que la silva fue concebida como fragmento de un poema magno, que nunca llegaría a completar, intitulado América. Ahora bien, ¿no podríamos pensar que realmente ese "poema magno" está configurado por el corpus poético de la literatura hispanoamericana que se generaría a partir del poema de Bello, es decir, a partir de la invitación, de la casi exigencia por él vertida, a que la Divina Lira se desplazase al nuevo continente?, ¿un texto lírico que él inició, amparándose en el legado clásico, pero cuya mayor fortuna estribaría en su progresiva continuación, más allá de su persona, allende la literal "Alocución”? Y, ¿no estaríamos de esta manera sancionando el verdadero sentido visionario, futurista al fin, del poema?

17 Bellini en Bello, ibid., 31-32.

18 Al final de su ensayo Tres poetas filósofos plantea George Santayana un pensamiento similar, que ha sido inspiración del mío. Al referirse al "necesario poeta" que otorgue voz y pensamiento a la filosofía del presente (no ya del pasado, como hicieran Lucrecio, Dante o Goethe), estampa el autor: “¿Quién será el poeta de esta nueva visión? No ha existido nunca, pero es, sin duda, necesario. Ha llegado el momento de que aparezca algún genio que reconstituya la destrozada imagen del orbe. (...) Podemos saludar desde lejos este genio que necesitamos. Como los poetas en el limbo de Dante, cuando Virgilio reaparece ante ellos, podemos saludarle diciendo: Onorate l'altissimo poeta. Honrad al más alto poeta, honrad al más alto poeta posible. Pero este supremo poeta está todavía en el limbo”. G. Santayana, Tres poetas filósofos, México, Porrúa, 1994, 115. 
Un arma colmada, plagada, plena de futuro fue la poesía para Andrés Bello. El "libertador artístico de América", en palabras de Henríquez Ureña. Tal vez el discurso con que este gran heredero de Bello iniciara, no azarosamente, el ciclo de sus conferencias en la cátedra Charles Eliot Norton de Universidad de Harvard, durante el curso académico 1940-41 sea, una vez más, la confirmación de mi hipótesis de lectura, de mi sospecha. Escuchemos al sabio dominicano:

En una época de duda y esperanza, cuando la independencia política aún no se había logrado por completo, los pueblos de la América hispánica se declararon intelectualmente mayores de edad, volvieron los ojos a su propia vida y se lanzaron en busca de su propia expresión. Nuestra poesía, nuestra literatura, habrían de reflejar con voz auténtica nuestra propia personalidad. Europa era vieja; aquí había una vida nueva, un nuevo mundo para la libertad, para la iniciativa y para la canción. Tales eran la intención y el significado de la gran oda, la primera de las Silvas americanas, que Andrés Bello publicó en 1823. Bello no era un improvisador, un advenedizo del romanticismo; era un sabio, un gran gramático, traductor de Horacio y de Plauto, explorador adelantado en las selvas todavía vírgenes de la literatura medieval. Su programa de independencia nació de una meditación cuidadosa y un trabajo asiduo. Desde entonces, nuestros poetas y escritores han seguido en la búsqueda, acompañados, en años recientes, por músicos, arquitectos y pintores. En las páginas que siguen hemos de ver cómo se ha cumplido este deber, y hasta qué punto se han colmado esas esperanzas ${ }^{19}$.

A partir de esta diáfana premisa, les he propuesto una relectura de la "Alocucion" de Andrés Bello en clave borgesiana. La de un solo autor inmortal, cuya voz multánime y polifónica se ramificaría a partir de su particular origen, fungiendo así de semilla y de puente. $Y$ si en la historia de la literatura europea ese inmortal al que siempre regresamos y al que siempre citamos y plagiamos - con mayor o menor fortuna, con menor o mayor conciencia - sería Homero, reconocido en la lluvia que reinventa el recuerdo de su Ilíada, posiblemente en la historia de la literatura hispanoamericana - de la que surge a partir de la independencia política y cultural- ese inmortal sea Andrés Bello, "el pensamiento vivo de Bello". Mascarón de proa en el navío transoceánico que lleva pintado en azul sobre láminas de metal el nombre de Poesía y cuya tripulación la capitanea un solo hombre transubstanciado en una irradiación de poetas. Los que construyeron, y aún prosiguen en su unánime labor, las rimas de la lira americana.

\section{BIBLIOGRAFÍA}

Arciniegas, G., El pensamiento vivo de Andrés Bello, Buenos Aires, Losada, 1958. Bello, A., Filosofía del entendimiento, en Obras Completas, vol. III, prólogo de J. D. García Bacca, Caracas, Ministerios de Educación, 1951.

19 Henríquez Ureña, op. cit., 10. 
-, Poesías, en Obras Completas, vol. I., prólogo de F. Paz Castillo, Caracas, Ministerio de Educación, 1952.

—, Obra literaria, selección y prólogo de P. Grases, cronología de O. Sambrano Urdaneta, Caracas, Ayacucho, 1979.

—, "Las repúblicas hispanoamericanas” y "Autonomía cultural de América”, en L. Zea, comp., Fuentes de la cultura latinoamericana, vol. I, México, FCE, 1995, 185-194.

-, Filosofía del entendimiento, introducción de J. Gaos, México, FCE, 2006.

-, Antología, edición, introducción y notas de G. Bellini, Madrid, Castalia, 2009.

Cussen, A., Bello y Bolivar, México, FCE, 1998.

Emerson, R. W., Ensayos, traducción de L. Echevarría, Madrid, Aguilar, 1962.

Henríquez Ureña, P., Historia cultural y literaria de la América Hispánica, edición de V. Cervera Salinas, Madrid, Verbum, 2007.

Menéndez Pelayo, M., Historia de la poesía hispano-americana, Madrid-Santander, CSIC, 1948.

Murillo, F., Andrés Bello, Madrid, Historia 16-Quorum, 1987.

Santayana, G., Tres poetas filósofos, México, Porrúa, 1994.

Uslar Pietri, A., “Andrés Bello el desterrado", en L. Zea, comp., Fuentes de la cultura latinoamericana, vol. II, México, FCE, 1995, 457-466. 